\title{
"DOS BENEFÍCIOS DE DEUS": TRÊS EDIÇÕES DE UM CAPÍTULO DO TRATADO MEDIEVAL PORTUGUÊS
}

\author{
Rita de Cássia Ribeiro de Queiroz*
}

\begin{abstract}
Resumo: O tratado "Dos benefícios de Deus" integra a obra da literatura medieval portuguesa intitulada Castelo perigoso, a qual é uma adaptação do texto francês escrito por Frère Robert, monge cartuxo, à sua prima Soeur Rose, da Ordem Fontevrault. A versão em língua portuguesa foi realizada no Mosteiro de Alcobaça, provavelmente no século XV, existindo dois códices (ALC 197 e ALC 214), os quais se encontram na Biblioteca Nacional de Portugal. O tratado "Dos benefícios de Deus" é o segundo na ordem dos textos que compõem a obra Castelo perigoso. Propõem-se, neste trabalho, três edições de um capítulo do tratado"Dos benefícios de Deus", a saber: uma edição conservadora ou semidiplomática; uma edição crítica, executada a partir da collatio entre os códices ALC 197 e ALC 214 e a edição realizada por Augusto Magne na década de 1940; e, por último, uma edição modernizada.
\end{abstract}

Palavras-chave: Crítica textual; edição; português medieval.

\section{Introdução}

A obra Castelo perigoso, tradução de uma longa epístola francesa Le chastel périlleux, escrita por Frère Robert, monge

\footnotetext{
* Universidade Estadual de Feira de Santana.
} 
cartuxo, para sua prima, Soeur Rose, freira da Ordem Fontevrault, encontra-se entre as obras do período medieval português. São conhecidos dezesseis apógrafos franceses, dentre os quais doze são classificados como manuscritos pessoais e quatro como adaptações ou refundições do original.

Em Portugal foi traduzida no Mosteiro de Alcobaça, sendo essa tarefa atribuída a frei Fructuoso, existindo atualmente dois manuscritos de posse da Biblioteca Nacional de Portugal, sob a cota ALC 197 e ALC 214. A versão portuguesa constitui, na realidade, uma adaptação livre do original francês, pois não há uma correspondência precisa em relação aos testemunhos franceses de que possa ter originado a tradução.

A obra Castelo perigoso consta de sete tratados, assim designados: 1. Castelo perigoso; 2. Dos benefícios de Deus; 3. Livro da consciência e do conhecimento próprio; $4 \mathrm{Da}$ amizade e das qualidades do amigo; 5 Das penas do inferno; 6 Das alegrias do paraíso; 7 Livro dos três caminhos e dos sete sinais do amor embebedado.

\section{O tratado "Dos benefícios de Deus"}

O tratado "Dos benefícios de Deus", assim como o primeiro, "Castelo perigoso", foi traduzido do francês. Contudo, as "Horas da cruz", que constam do original francês, foram suprimidas da tradução portuguesa. Segundo Martins, ${ }^{1}$ este mesmo texto encontra-se em Laudes e cantigas espirituais, da primeira metade do século XV, de Mestre André Dias, em verso português, que são parecidas com as que figuram no Livro das horas, em latim. Esse tratado desdobra, amplamente, um trecho do primeiro acerca da comunhão (capítulo 47). O próprio autor, a partir de uma nota no capítulo 69 acentua o fato, levando-se a supor ser ele o autor

\footnotetext{
${ }^{1}$ MARTINS. Os sete tratados cartusianos do códice CCLXXVI/199, de Alcobaça, p. 167.
} 
do primeiro tratado. Nos capítulos 70 a 81 são apresentados os doze frutos espirituais do Santíssimo Sacramento, voltados para a Paixão.

\subsection{A tradição da obra}

Integram a tradição da obra dois manuscritos alcobacenses: os códices 199 (antigo 276) e 214 (antigo 275).

O cód. 199 é constituído por 160 fólios membranáceos, medindo aproximadamente $285 \mathrm{~mm} \times 200 \mathrm{~mm}$, repartidos em vinte cadernos, de oito fólios cada um, com a ligadura em cordão. Consta do primeiro caderno a "tábua de capítulos", o qual é precedido por duas folhas de guarda em pergaminho, que contêm um texto em latim, em duas colunas, de teor religioso, porém não identificado, seguidas de duas folhas de guarda em papel. A primeira folha de guarda em papel traz, a lápis, a paginação "02", seguida, a lápis azul, pelas cotas "XIV" e "199". A segunda folha, além da paginação " 03 ", contém o seguinte texto:

\{Cod. 276\}

Castello Perigozo,

Livro Ascético,

que consta de 200 Capitulos, nos quaes se moraliza aquella parte do Evangelho de S. Lucas, que a Igreja canta no dia da Assum=

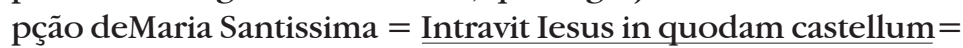

Composto e escripto por Fr. Fructuozo Monge Alcobacense natural de S. Pedro doSul, que o acabou de escrever na Pascoa de1362, como cons= ta de humaRubrica, que está no fim destecodigo.

Depois do ultimo Capitulo do sobreditoLivro estáhumbreve Tratado es= cripto da mesma mão, no qual oAuthor para promover á perseverança no bem, e ao augmento no amor deDeus trans creve aEx pozição de Origenes sobre aquellas palavras do Evangelho deS. João Cap. 20. = Maria stabat ad monumentum foris plorans =, e discorresobre a mesmaExpozição. 
Este mesmoLivro aqui intitulado_Castello perigozo_inculca Bar= boza na suaBiblioteca Luzitana desta maneira = Castello Espiritual composto por Fr.Carlos de Lisboa,o qual em 199_Capitulos explica oEvan gelho-Intravit Iesus in quodamCastellum - com reflexoens doutas e pie $=$ dozas.

Os cadernos estão completos, em bom estado de conservação e bem ordenados, não havendo lacunas entre eles. A encadernação, no entanto, apresenta problemas de conservação. A numeração dos fólios se dá da seguinte forma: o primeiro caderno traz, no ângulo superior direito, uma numeração arábica em preto; os cadernos seguintes apresentam, além da numeração já citada, uma romana original em tinta vermelha, no centro da margem superior. Além dessas, há outra numeração a lápis em todos os fólios, divergindo das demais em oito fólios.

O cód. 199 apresenta ainda as seguinte características físicas: a mancha escrita mede aproximadamente $195 \mathrm{~mm} \times 130 \mathrm{~mm}$; a letra do texto é a escrita gótica semicursiva da primeira metade do século XV; o número de linhas dos fólios oscila entre 20 e 24; a "tábua dos capítulos" está escrita em tinta vermelha e preta; o primeiro fólio traz a letra $E$ filigranada em vermelho e azul, com desenho de um castelo ao fundo; as margens esquerda, direita e inferior, que contornam o texto, apresentam decoração nas mesmas cores; as letras capitais, em todos os fólios, apresentamse ornamentadas em tinta vermelha e azul, havendo uma variação (ora o adorno é vermelho com fundo azul, ora é azul com fundo vermelho); as letras maiúsculas do corpo do texto estão em tinta preta adornadas de vermelho; os capítulos, as citações em latim, as rubricas e a numeração romana estão em tinta vermelha; em alguns fólios os capítulos são separados por ornamentos em tinta vermelha que podem ocupar o espaço da sequência de uma linha ou o deixado em branco entre uma linha e outra.

O tratado "Dos benefícios de Deus" está assim distribuído: capítulos LXVII a LXXXVIII, fólios $42 \mathrm{v}$ a $46 \mathrm{v}$. 


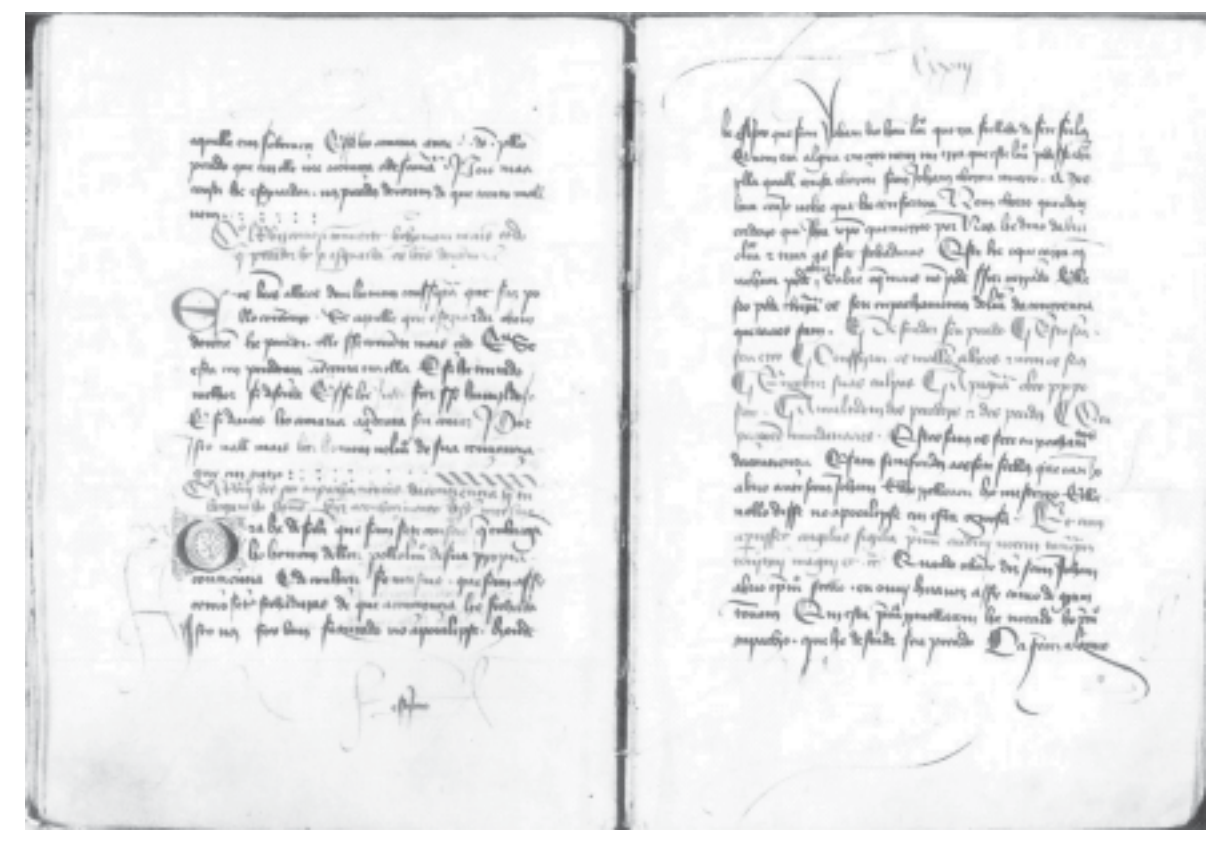

Figura 1: Fólios 72v e 73r do cód. 199

O cód. 214 compõe-se de 100 folhas em papel, medindo aproximadamente $292 \mathrm{~mm} \times 207 \mathrm{~mm}$. Precedem ao texto duas folhas de guarda em papel, a segunda destas apresenta a seguinte nota escrita a lápis: "A fol. 55 tem a marca d'água mão com estrela que aparece em obras do sec. XV". Há outra marca d'água n.$^{\circ} 11410$ (do catálogo de Briquet $^{2}$ ): uma mão de cinco dedos com a flor de cinco pétalas na vertical do dedo médio. Em seguida há uma folha com uma inscrição, provavelmente escrita pela mesma mão que escreveu a encontrada no cód. 199.

O códice encontra-se em mau estado de conservação, havendo folhas ilegíveis em decorrência de manchas de umidade. Algumas partes do texto apresentam-se rasgadas e/ou corroídas

\footnotetext{
${ }^{2}$ BRIQUET. Les filigranes.
} 
pela abrasão da tinta. O cód. 214 traz ainda, ao final, duas folhas de guarda em papel. Não apresenta a "tábua de capítulos" nem tampouco o comentário de encerramento que consta do cód. 199.

O cód. 214 apresenta a ainda as seguinte características físicas: a mancha escrita mede aproximadamente $280 \mathrm{~mm} \times 210 \mathrm{~mm}$; a letra do texto é a escrita gótica cursiva da segunda metade do século XV ou mesmo do início do século XVI, provavelmente a cinco mãos; o número de linhas dos fólios é oscilante; em cada folha há três numerações: uma arábica, em tinta preta, no ângulo superior direito, e duas a lápis (uma no ângulo inferior direito e a outra no ângulo superior esquerdo, provavelmente posteriores); não há ornamentações; o texto está todo escrito em tinta preta.

O tratado "Dos benefícios de Deus" está assim distribuído: capítulos LXVII a LXXXVIII, fólios 65v a 69r.

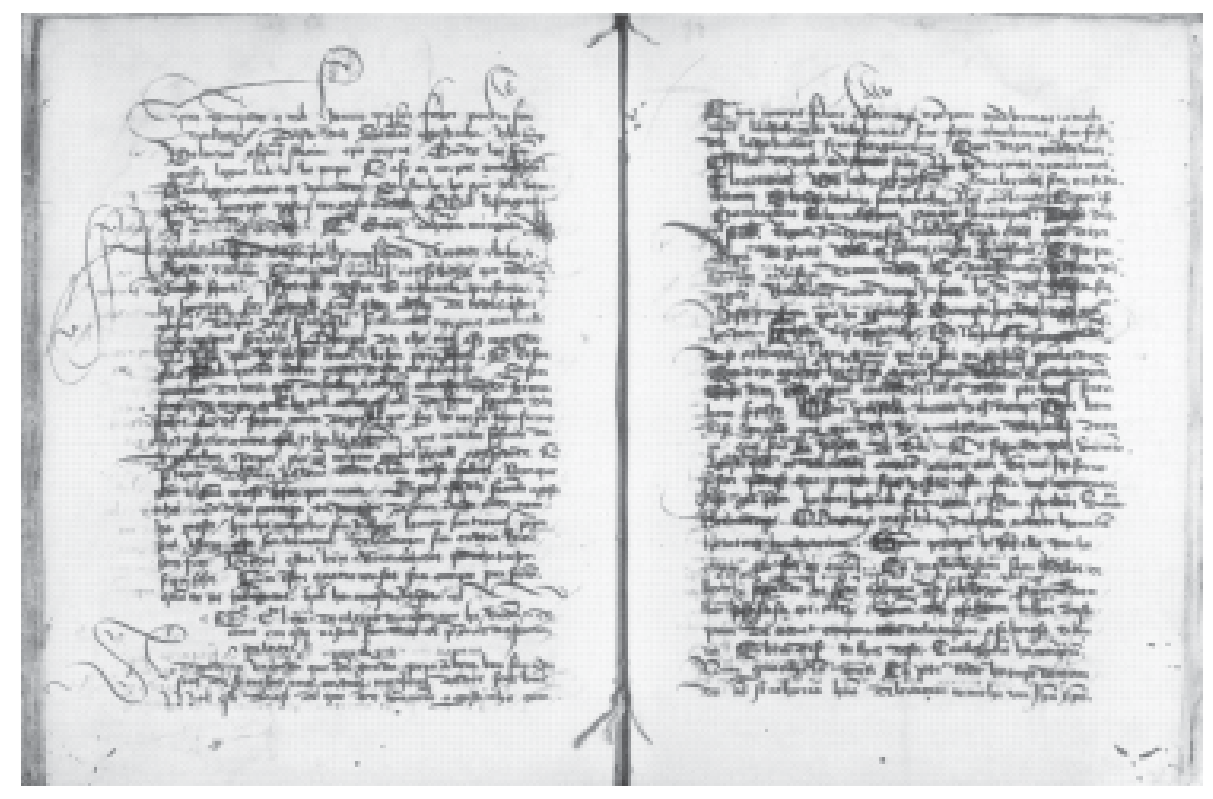

Figura 2: Fólios 17v e 18r do cód. 214 


\section{As edições}

\subsection{Critérios}

\subsection{Edição semidiplomática}

Optou-se por uma edição semidiplomática por ser um tipo de edição que oferece ao leitor, leigo ou especializado, o conhecimento do modo de escrever do homem de qualquer tempo, seja ele medieval, antigo, renascentista, moderno ou contemporâneo. Assim, a interferência do editor é mínima, sendo apenas feita em casos previamente identificados. Fez-se, então, uma lição conservadora, mantendo-a o mais próximo possível do original, destinando-a, assim, a quaisquer estudiosos que por ventura se interessem pelo teor dos tratados, pois os mesmos podem ser objeto de estudo de linguistas, historiadores, religiosos, místicos, dentre outros, sem as dificuldades de leitura que um texto medieval oferece.

\subsubsection{Critérios para a edição semidiplomática}

a) Transcrição rigorosa do texto original, fólio a fólio, linha a linha.

b) Respeito absoluto pela ortografia e pontuação do texto original:

Este critério constitui a essência do tipo de edição que ora se apresenta. Visa-se, com o respeito pela ortografia e pela pontuação, oferecer a quaisquer estudiosos ou ao leitor comum, a maneira de escrever do homem medieval, verificando-se com isso as suas imprecisões, flutuações de critérios, incongruências, ou até mesmo o seu nível de aprendizagem ortográfica. Nesse caso, manter-se-ão, conforme o original, as maiúsculas e minúsculas; as palavras unidas e as separadas; as vogais e consoantes geminadas; a oscilação entre $\langle\mathrm{i}\rangle,\langle\mathrm{y}\rangle$ e $\langle\mathrm{j}\rangle,\langle\mathrm{u}\rangle$ e $\langle\mathrm{v}\rangle$, e marca de nasalidade: $\langle\sim>,<\mathrm{n}\rangle,<\mathrm{m}\rangle$. 
c) Desenvolvimento das abreviaturas, apresentando-as em itálico e negrito:

Desenvolveram-se as abreviaturas por um simples detalhe: o seu uso, indiscriminado na Idade Média, oferece dificuldade para uma leitura nos nossos dias. Como também se constitui em essência de qualquer tipo de edição ajudar ao leitor a uma maior compreensão do texto original, optou-se por desenvolvê-las, tornando assim o texto inteligível. Destarte, as letras abreviadas aparecem em itálico e negrito, seguindo-se rigorosamente então o critério anterior, pois se tem a visualização gráfica da ortografia e dos modos de expressão usados no texto original.

d) Manutenção dos numerais:

Os numerais são transcritos tal e qual aparecem no texto original. Sabe-se que eles são uma forma de abreviatura, porém mantê-los como foram escritos favorece a compreensão do modo de contar e de exprimir da época.

e) Colocação entre colchetes de tudo o que tenha sido interpretado pelo editor ou acrescentado ao texto original:

A utilização deste critério tem por finalidade apresentar ao leitor as intervenções feitas pelo editor nos seguintes casos: omissões devido a rasuras, falhas ou destruição causada pelo tempo.

f) Numeração das linhas:

Com vistas a facilitar a leitura, o texto é numerado de cinco em cinco linhas, fólio por fólio. 


\subsection{Edição crítica}

\subsubsection{Designação das versões}

As versões foram designadas da seguinte forma:

A: Ms. 199 (ant. 276) - Biblioteca Nacional de Portugal - Cota: ALC 199 - Capítulos: 67 a 115;

B: $\quad$ Ms. 214 (ant. 275) - Biblioteca Nacional de Portugal - Cota: ALC 214 - Capítulos: 67 a 115;

C: Edição de Augusto Magne - Capítulos 67 a 89 (cap. 67: Verbum: Boletim de Filologia, v. 3, n. 6, 1946, p. 201; caps. 68 a 89: Verbum: Boletim de Filologia, v. 3, n. 7, 1946, p. 298-307).

\subsubsection{Critérios para a edição crítica}

a) Texto de base

Foi adotado como texto de base (codex optimus) o cód. 199, por ser o mais antigo e mais completo da tradição medieval portuguesa do Castelo perigoso. O cód. 214, de datação posterior, apresenta-se incompleto, sendo utilizado para a elaboração do aparato crítico, no qual também figura a leitura feita por Augusto Magne. As variantes entre os manuscritos 199 e o 214 são apontadas no aparato crítico, ao lado de outras lições que porventura tenham alterado o sentido do texto.

b) Transcrição do texto de base, fólio a fólio:

Optou-se por esse tipo de apresentação, visando a visualização gráfica do texto de base juntamente com o seu aparato crítico, não sendo necessário ter-se de recorrer a outra página. Sendo assim, cada fólio é editado criticamente em uma única página.

c) Modernização da ortografia

Na edição crítica, optou-se pela modernização ortográfica de acordo com a norma atual, desde que esta não interfira nas questões de pronúncia da época. Contudo, a incidência deste 
critério será apontada no aparato crítico. A seguir, os princípios norteadores utilizados:

c.1) Vocalismo

- Os grafemas alógrafos $<\mathrm{i}\rangle,<\mathrm{j}>\mathrm{e}<\mathrm{y}>$ ocorrem indistintamente, optando-se, nesse caso, pela regularização através da forma mais moderna atestada no texto de base, ou seja, por $<\mathrm{i}>$.

- As vogais geminadas foram simplificadas.

- Regularização da marca de nasalidade nas vogais, conforme ortografia atual, nos seguintes casos:

i. Em posição final de sílaba, uniformiza-se com $<$ m $>$ ou $<$ n $>$ a depender da consoante que ocorra a seguir;

ii. Em posição final a nasalidade é marcada por $<\mathrm{m}>$;

iii. Manteve-se o uso do til nas vogais cuja substituição levaria a uma pronúncia inexistente na época;

iv. A oscilação na marca de nasalidade das vogais diante de $<\mathrm{h}\rangle$, que ora aparece $\langle\mathrm{nh}\rangle$, ora $<\sim \mathrm{h}>$, ora $<\mathrm{mh}>$ foi regularizada $\mathrm{em}<\mathrm{nh}>$.

c.2) Consonantismo

- Os grafemas alógrafos $<\mathrm{u}>\mathrm{e}<\mathrm{i}>$ com valor consonântico foram transcritos respectivamente como $<\mathrm{v}>\mathrm{e}<\mathrm{j}>$;

- Restauração do uso das consoantes nos seguintes casos:

i. Oscilação na utilização de consoantes geminadas e simples, optando-se pela simples;

ii. Simplificação das geminadas;

iii. Uso do h inicial e medial. 
c.3) União e separação de palavras

As palavras unidas foram separadas e as separadas foram unidas, conforme regra ortográfica vigente.

c.4) Acentuação das palavras

No texto de base só aparece como marca de acentuação o traço sobreposto às vogais indicando nasalidade. Restaurou-se a acentuação conforme ortografia atual.

c.5) Uso da cedilha

Regularizou-se o emprego da cedilha, conforme norma atual, somente nos casos em que houve oscilação do copista.

c.6) Maiúsculas e minúsculas

Regularizou-se o uso de maiúsculas e minúsculas de acordo com o critério atual de sua distribuição.

c.7) Acréscimos

Utilizaram-se colchetes uncinados para indicar os acréscimos feitos por conjectura, devido às razões mencionadas nos critérios para a edição semidiplomática.

c.8) Pontuação e divisão do texto

Manteve-se a pontuação original do texto, modernizandose os sinais utilizados no manuscrito. Conservou-se a divisão do texto original.

\section{c.9) Citações}

Conservaram-se as citações na língua em que figuram, recorrendo-se ao uso do itálico para destacá-las, assim como facilitar a sua leitura. Manteve-se a ortografia nas citações em latim.

c.10) Aparato crítico

- Figuram no aparato as intervenções do editor, as variantes de $\mathbf{B}$ e de $\mathbf{C}$. O aparato vem em seguida ao 
texto de base, sendo introduzido pelo número da linha, ao qual seguem-se a lição crítica e o separador ], as siglas dos testemunhos da tradição (A e B) e C, representando a leitura de Padre Augusto Magne. Em se tratando de um aparato negativo, apresentam-se apenas as lições divergentes. Contudo, nos casos de intervenção do editor, esta também é apresentada.

- As abreviaturas desenvolvidas não figuram no aparato crítico.

- Quando a palavra ou trecho não consta do testemunho, utilizou-se o sinal $Æ$ para indicar a sua inexistência.

- Figuraram no aparato crítico todos os casos não previstos nos critérios mencionados.

\subsection{Edição modernizada}

Assim como a edição crítica, a edição modernizada tem por texto de base o manuscrito 199. Optou-se por apresentar também esta edição com o intuito de oferecer ao leitor menos acostumado com os estágios anteriores da língua portuguesa uma lição em que a atualização ortográfica fosse total, além do esclarecimento em relação às fontes bíblicas, sejam elas em latim ou português, bem como a significação de determinados termos. Estas informações constam em notas de rodapé.

\subsubsection{Critérios para a edição modernizada}

a) Vocalismo: os ditongos orais ou nasais estão representados nas formas atuais.

b) Consonantismo: as consoantes são transcritas conforme a ortografia atual.

c) Acentuação: os acentos são utilizados de acordo com a ortografia atual. 
d) Uso da cedilha: o emprego da cedilha foi regularizado de acordo com a ortografia atual.

e) Acréscimos: utilizaram-se os colchetes uncinados para indicar os acréscimos feitos por conjectura.

f) Outras intervenções: as palavras estrangeiras figuram em itálico e entre aspas simples e duplas; as citações latinas foram corrigidas de acordo com as fontes, apresentadas em nota de rodapé; foram atualizadas as palavras gramaticais; foram conservadas as palavras lexicais, constando em nota de rodapé sua significação ou forma atual; os substantivos próprios foram atualizados; foram atualizados os sufixos modo-temporais e número-pessoais das formas verbais.

g) Pontuação e divisão do texto: a pontuação do manuscrito foi mantida, sempre que possível, contudo foram introduzidos ou suprimidos sinais de pontuação nos casos em que isso foi necessário para a compreensão do texto; a divisão do texto é mantida de acordo com o manuscrito, em capítulos numerados e em negrito; as mudanças de fólio e de face (recto e verso) são indicadas através de colchetes retos em negrito.

\subsection{Texto das edições}

\subsubsection{Edição semidimplomática do capítulo 67}

3.2.1.1. Cód. 199

Capitulo LXVII comoamemoria dos benefiçios que nos deus fez he muito boa

DE todollos benefiçios de nosso Senhor Ihesu christo que nos mouem aoamar. ho dessua paixom he ho mais piadoso . E odeque os pelle jadores de deus sedeuiã armar contra seus Imiigos Por jsto disse sam Pedro. Ihesu christo sofreo por Nos da quells penssamẽtos uos armaae . EPor que homem nom sepossa escusar . de pequena me moria ou 
10 de mingua despaço . eu quero aquy meter breuemẽte amemo ria de sua paixom . E sam assy como huas oras pera as de uotas pessoas que nom entendem latym . demouer adeuaçõ e conpaixom . e sam thiradas das oras dolatim que

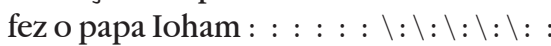

15 Aqui falleçem as oras dacruz que nom forom tornadas em purtugues porque eram em rrimãço em framçes E nom pareceriombem sem rrimo $\backslash \backslash \backslash \backslash \backslash \backslash \backslash \backslash \backslash$

\subsubsection{Cód. 214}

Capitulo LXVII . comoa memoria dos be ne fiçios que nos deus fez he muito boa.

Detodolos bene fiçios de Noso Señor que nos mouẽ ao amor ho da sua paixam he omais piadoso .

De to do los bene ficios

[44r] e ode que os pellejadores dedeus sse deuiã armar cõtra seus jmiguos por jsto disse ssam paulo jhesuu christo ssofreo por Nos daquelles pensamẽtos vos armaae e por que homẽ Nom sseposa escusar depequena memoria ou de migua despaço eu quero aquy meter breue mẽte amemoria desua paixã essam assy como oras perasdeuotas pessoas quenão entẽdem llatym demouer adeuaçam e com paixam essam tyradas das oras do llatym que fez opapa joam

Aquy falleçem as oras da cruz que nom foram tornadas em purtugues por que eram em rromãçeo em françes $\mathrm{e}$ Nom pareceriam bem ssem rrimo

\subsubsection{Edição crítica do capítulo 67}

\section{Capítulo LXVII Como a memória dos benefíçios que nos Deus fezé muitoboa.}

De tôdolos benefíçios de Nosso Senhor Jesu Cristo que nos movem ao amar, o de sua paixom é o mais piadoso, e o de que os pelejadores de Deus se deviam armar contra seus imigos. Por isto disse Sam Pedro: "Jesu Cristo sofreo por nós, daqueles

5 pensamentos vos armae." E por que homem nom se possa escusar de pequena memória ou de míngua d'espaço, eu quero aqui meter brevemente a memória de sua paixom. E sam assi como ũas horas pera as devotas pessoas que nom 
entendem latim, demover a devaçom e compaixom, e sam tiradas das horas do latim que fez o Papa Joam.

10

Aqui faleçem as horas da cruz que nom forom tornadas em purtuguês porque eram em rimanço em françês e nom pareceriom bem sem rimo.

2. Nosso] B: Noso; Jesu Cristo] B: Ø; ao amar] B: ao amor, C: a o amar; 3. paixom] B: paixam; 5. imigos] B: jmiguos; daqueles] C: daquele; 6. armae] B: armaar; 7. míngua] B: mĩgua; 8. paixom.] B: paixã; ũas] B: Ø; pera as] B: peras; nom] B: não; 9. devaçom] B: deuaçam, C: devoçom; compaixom] B: com paixam; o Papa] C: a papa; 10. forom] B: foram; purtuguês] C: português; 11. rimanço] B: rromãçeo; pareceriom] B: pareceriam.

\subsubsection{Edição modernizada do capítulo 67}

\section{Capítulo LXVII Como a memória dos benefícios que Deus nos fezé muitoboa.}

De todos os benefícios de Nosso Senhor Jesus Cristo que nos movem ao amar, o de sua Paixão é o mais piedoso, e o de que os pelejadores de Deus se deviam armar contra seus inimigos. Por isto, disse São Pedro: "Jesus Cristo sofreu por nós, daqueles pensamentos vos armai." ${ }^{4} \mathrm{E}$, porque homem não se possa escusar de pequena memória ou de míngua ${ }^{5}$ de espaço, eu quero aqui meter brevemente a memória de sua Paixão. E são assim como umas horas para as devotas pessoas que não entendem latim, demover ${ }^{6}$ a devoção e compaixão, e são tiradas das horas do latim que fez o Papa João. ${ }^{7}$

${ }^{3}$ Pedro: Apóstolo de Jesus Cristo.

4 "Com efeito para isto é que vós fostes chamados, pois que o Cristo também sofreu por nós, deixando-vos o exemplo, para que sigais as suas pegadas.": I Pedro 2, 21 / "Tendo, pois, Cristo, sofrido na carne, armai-vos também vós do mesmo pensamento: aquele que sofreu na carne, deixou de pecar, para viver durante o tempo que lhe resta na carne, não segundo as paixões do homem, mas segundo a vontade de Deus.” I Pedro 4, 1-2 / “... mas aniquilou-se a si mesmo, tomando a forma de servo, tornando-se semelhante aos homens e sendo reconhecido por condição como homem. Humilhou-se a si mesmo, fez-se obediente até a morte e morte de cruz.": Filipenses 2, 7-8/ "Mas Deus demonstrou seu amor para conosco porque morreu por nós quando ainda éramos pecadores.": Romanos 5, 8.

${ }^{5}$ Míngua: falta

${ }^{6}$ Demover: dissuadir

${ }^{7}$ Papa João XXII (1244 - 1334): Francês, segundo papa de Avignon, eleito em 7 de agosto de 1316, foi um dos poucos papas acusados de heresia, neste caso 
Aqui falecem as Horas da Cruz que não foram tornadas em português porque eram em romanço, ${ }^{8} \mathrm{em}$ francês, e não pareceriam bem sem rimo.

\section{Considerações finais}

Buscou-se apresentar as três edições que foram realizadas com o tratado "Dos benefícios de Deus", embora de forma reduzidíssima, já que o tratado contém mais capítulos.

Destarte, objetivou-se oferecer três modelos de edição: a semidiplomática - para que o leitor possa observar toda a escritura de um texto medieval, escrito em português arcaico; a edição críticana qual se apresentam as variantes em relação ao texto de base, ou seja, ao manuscrito mais antigo (o cód. 199), em comparação com a cópia realizada posteriormente (o cód. 214), e a edição parcial feita no Brasil, nos anos 40 do séc. XX, pelo padre Augusto Magne; e uma edição modernizada, que traz informações contidas em notas de rodapé, de teores diversos, tais como: notas lexicais; notas culturais; notas referenciais - tanto de citações bíblicas literais quanto de paralelas, objetivando-se com isso esclarecer, ao máximo possível, o conteúdo dos tratados, que são basicamente de cunho moral e religioso.

devido à crença declarada de que os santos não contemplam Deus (a visão beatífica) antes do Juízo Final. Entre seus atos consta a condenação de 22 sentenças de mestre Eckart (=1327), o famoso místico alemão. Morreu em 4 de dezembro de 1334, aos 89 anos.

${ }^{8}$ Romanço: romance, cada uma das variedades surgidas da evolução do latim falado pelas populações que ocupavam as diversas regiões que formavam o Império Romano, e que se constituiu na fase preliminar de uma dada língua românica. 
Résumé: Le traité "Dos benefícios de Deus" intègre l'œuvre de la littérature médiévale potugaise Chastel périlleux, qui est une adaptation du texte français écrit par Robert Frère, moine chartreux, à sa cousine Sœur Rose, de l'Ordre Fontevrault. La version en langue portugaise a été réalisée au Monastère d'Alcobaça, probablement au XVe siècle: il y a deux codex (ALC 197 et ALC 214), qui sont à la Bibliothèque Nationale du Portugal. Le traité "Dos benefícios de Deus" est le deuxième dans l'ordre des textes qui constituent l'œuvre Chastel périlleux. Sont proposées dans le présent travail trois éditions d'un chapitre du traité "Dos benefícios de Deus", à savoir: une édition conservatrice ou semidiplomatique; une édition critique, faite à partir de la collation des manuscrits entre les codex 197 et 214 et l'édition faite par Augusto Magne en 1940; et, enfin, une édition modernisée.

Mots-clés: Critique textuelle; édition; portugais médiéval.

\section{Referências}

BRIQUET, C. M. Les filigranes: dictionnaire historique des marques du papier dès leur aparition vers 1282 jusqu'en 1600. Paris: Picard, 1907. 4 vols.

MAGNE, Augusto. Castelo perigoso. Revista Filológica, Rio de Janeiro, v. 4, n. 15, p. 183-202, 1942.

MAGNE, Augusto. Castelo perigoso. Revista Filológica, Rio de Janeiro, v. 5 , n. 18 , p. 81-87, 1942.

MAGNE, Augusto. Castelo perigoso. Verbum: boletim de filologia, Rio de Janeiro, v. 2, p. 116-123, 23-238, 345-353, 458-469, 1945.

MAGNE, Augusto. Castelo perigoso. Verbum: boletim de filologia, Rio de Janeiro, v. 3, p. 79-89, 191-201, 298-307, 1946.

MARTINS, Mário. Os sete tratados cartusianos do códice CCLXXVI/199, de Alcobaça. In: Estudos de literatura medieval. Braga: Cruz, 1956. p. 159-182. 
QUEIROZ, Rita de Cássia Ribeiro de. "Dos benefícios de Deus", "Livro da consciência e do conbecimento próprio", "Da amizade e das qualidades do amigo": edição e vocabulário onomasiológico de três tratados da obra ascético-mística "Castelo perigoso" (Cód(s). ALC 199 e ALC 214). 2002. $468 \mathrm{f}$. Tese (Doutorado em Letras) - Departamento de Letras Clássicas e Vernáculas, Faculdade de Filosofia, Letras e Ciências Humanas, Universidade de São Paulo, São Paulo.

SANTANA NETO, João Antônio de. Duas leituras do tratado ascéticomístico "Castelo Perigoso". 1997. 310 f. Tese (Doutorado em Letras) Departamento de Letras Clássicas e Vernáculas, Faculdade de Filosofia, Letras e Ciências Humanas, Universidade de São Paulo, São Paulo.

Recebido para publicação em 27 de setembro de 2010 Aprovado em 21 de dezembro de 2010 